\title{
A clip-on electroosmotic pump for oscillating flow in microfluidic cell culture devices
}

\author{
Katarina Bengtsson ${ }^{1,2} \cdot$ Jonas Christoffersson ${ }^{3} \cdot$ Carl-Fredrik Mandenius $^{3} \cdot$ Nathaniel D. Robinson $^{1,2} \oplus$
}

Received: 4 November 2017 / Accepted: 8 February 2018 / Published online: 19 February 2018

(c) The Author(s) 2018. This article is an open access publication

\begin{abstract}
Recent advances in microfluidic devices put a high demand on small, robust and reliable pumps suitable for high-throughput applications. Here we demonstrate a compact, low-cost, directly attachable (clip-on) electroosmotic pump that couples with standard Luer connectors on a microfluidic device. The pump is easy to make and consists of a porous polycarbonate membrane and poly(3,4-ethylenedioxythiophene) polystyrene sulfonate (PEDOT:PSS) electrodes. The soft electrode and membrane materials make it possible to incorporate the pump into a standard syringe filter holder, which in turn can be attached to commercial chips. The pump is less than half the size of the microscope slide used for many commercial lab-on-a-chip devices, meaning that these pumps can be used to control fluid flow in individual reactors in highly parallelized chemistry and biology experiments. Flow rates at various electric current and device dimensions are reported. We demonstrate the feasibility and safety of the pump for biological experiments by exposing endothelial cells to oscillating shear stress (up to $5 \mathrm{dyn} / \mathrm{cm}^{2}$ ) and by controlling the movement of both micro- and macroparticles, generating steady or oscillatory flow rates up to $\pm 400 \mu \mathrm{L} / \mathrm{min}$.
\end{abstract}

\section{Introduction}

Microfluidic cell culture devices typically rely on some transport mechanism to drive flow through a cell culture compartment. The transport can be driven through mechanical action, e.g., syringe pumps or peristaltic pumps, or using a nonmechanical technique, such as electroosmosis- or hydrodynamic pressure-based pumps, e.g., pneumatic or gravity-driven pumps. In each of these examples (with a few

Katarina Bengtsson and Jonas Christoffersson have contributed equally to this work.

Electronic supplementary material The online version of this article (https://doi.org/10.1007/s10404-018-2046-4) contains supplementary material, which is available to authorized users.

Nathaniel D. Robinson

natro@ifm.liu.se

1 Transport and Separations Group, Department of Physics, Chemistry and Biology, Linköping University, Linköping, Sweden

2 LunaMicro AB, Teknikringen 7, Linköping, Sweden

3 Division of Biotechnology, Department of Physics, Chemistry and Biology, Linköping University, Linköping, Sweden exceptions), an off-chip pump or pressure source drives the flow. Generating oscillatory flow requires the pump direction to be periodically reversed or requires sophisticated flow handling with mechanical valves. One of the major benefits of microfluidics is the small quantity of fluid required $(\mathrm{pL}-\mu \mathrm{L})$, minimizing both cost and waste, particularly with rare reagents such as specially synthesized pharmaceutical candidates. Hence, a pump and its connecting tubing preferably do not require significantly more fluid than the chip it is driving. On the other hand, for cell cultures, a minimum volume of cell culture medium must be present to ensure an isotonic and nutrient-rich environment and provide the sample volumes necessary for chemical analysis (ELISA, HPLC, mass spectrometry, etc.). Off-chip pumps require tubing between the pump and chip, which can lead to "dead volumes" of several mL. Pumps that can handle small volumes with high precision are relatively expensive. Several on-chip pumps reported recently, such as monolithic microfabricated pumps, (Unger et al. 2000) electrochemically actuated pumps, (Suzuki and Yoneyama 2003) and acoustofluidic pumps (Huang et al. 2014), address these issues. These pumps require only minute amounts of fluid and can be directly integrated into the microfluidic device. However, these pumps specialize in delivering low volumes of fluids at low flow rates and are not readily compatible 
with commercial microfluidic devices. To fill this gap, we have created a compact, low-cost, clip-on (attachable) electoosmotic pump that is approximately the same size as a chip (less than half the size of a standard microscope slide), operates at high flow rates without moving parts and without any electric field over the cells in the chip and connects directly to the Luer connector of a microfluidic device without the use of tubing. Furthermore, this electroosmotic pump can be reversed simply by reversing the bias of the applied potential, simplifying the generation of oscillatory flow.

Electroosmotic pumps (EOPs) operate on the principle of electroosmosis, which generates liquid flow through microfluidic channels when an electric field is applied along the channel (Kirby 2010). Electroosmosis is driven by the motion of ions that congregate at the interface between the liquid and the (chemically) charged channel walls. These mobile ions move toward the oppositely charged electrode and, in channels with a diameter $<200 \mu \mathrm{m}$, drag enough fluid with them to create flow. EOPs are usually made in capillaries or chambers filled with porous glass, but can also be made using other porous substrates (Brask et al. 2005; Kwon et al. 2012; Nilsson et al. 2015; Sachan et al. 2014; Snyder et al. 2013). Compared to several other types of pumps, the advantages of EOPs demonstrate a well-controlled (steady or pulsatile) flow, a small footprint and very small dead volume. For cell culture devices, a few EOPs have been demonstrated with cells in suspension (Emmelkamp et al. 2004; Li and Harrison 1997; Xuan and Li 2005). For cells attached to surfaces, examples include the EOP with a concentration gradient generator by Glawdel et al. (2009) and the electroosmotic diode pump with nanoliter precision by Chang et al. (2014). All these EOPs operate at flow rates below a few $\mu \mathrm{L}$ per minute. To date, relatively few examples of the use of EOPs for cell culture devices can be found, possibly because EOPs operate best at low salt concentration and are therefore not suitable for pumping cell culture medium. Furthermore, operating EOPs with traditional metal electrodes gives rise to water electrolysis and the subsequent generation of $\mathrm{H}_{2}$ and $\mathrm{O}_{2}$ bubbles and change in $\mathrm{pH}$. These bubbles can disrupt flow, and the $\mathrm{pH}$ changes can damage the cells. It has previously been shown that replacing metal electrodes with poly(3,4-ethylenedioxythiophene) polystyrene sulfonate (PEDOT:PSS) electrodes can reduce the amount and impact of water electrolysis in electrokinetic applications (Bengtsson et al. 2014; Bengtsson and Robinson 2017; Erlandsson and Robinson 2011). Further drawbacks of EOPs, as outlined by Byun et al. (2014), include the risk of fouling of the pump by accumulation of, e.g., proteins and cell debris from the medium, as well as electrical damage to the cells in cases where the electrical field is applied over the cell culture to drive the flow.

To overcome these challenges, we have created an EOP that can operate at high flow rates, comparable to other types of pumps used in microfluidics, without the need to apply an electric field over the cells and with low risk of fouling or causing air bubbles to interfere with the cells. This EOP design can generate high oscillating flow rates with a small dead volume, yielding two advantageous consequences: (1) it provides opportunities to study shear stress effects across the perfused cells, and (2) external metabolites or other excreted molecules can accumulate in the small volumes of a micro-device to reach levels detectable with current analytical methods.

Many cells, such as endothelial cells, cardiac cells, hepatic cells, as well as kidney cells, are affected by shear forces during their differentiation and maturation, motivating the creation of complex shear profiles in microfluidic devices (Esch et al. 2015; Jackman et al. 2016; Jang et al. 2013; Schimek et al. 2013). More specifically, steady shear stress, ranging from 5 to $20 \mathrm{dyn} / \mathrm{cm}^{2}$, has been reported to align endothelial cells in the direction of flow ( $\mathrm{Li}$ et al. 2005; Schimek et al. 2013) and tighten intercellular connections, which has been used to mimic the tight barrier between the blood and the brain (Booth and Kim 2012). However, compared to steady flow, alternating flow (in which the flow direction is repeatedly reversed) does not cause cell alignment, but, like steady flow, influences cell physiology and gene expression (Deguchi et al. 2005; Franzoni et al. 2016). Oscillatory flow of about $\pm 4 \mathrm{dyn} /$ $\mathrm{cm}^{2}$ occurs at branches in blood vessels and seems to play a key role in the development of atherosclerosis (Davies et al. 2013; Malek et al. 1999). In addition to creating a physiologically relevant environment, oscillating flow (shear) allows the volume of fluid exposed to the cells to be minimized, making it possible to concentrate the minute amounts of biomarkers excreted by the cells, making them easier to identify and quantify.

In this paper, we demonstrate a clip-on (no tubing) electroosmotic pump that generates flow rates up to $400 \mu \mathrm{L} /$ min. We have combined advantages of an off-chip pump that handles large volumes $(1-2 \mathrm{~mL})$ with the compact size and proximity of an on-chip pump by placing our pump directly on top of the chip. The pump is the size of a syringe filter holder, with integrated PEDOT:PSS electrodes separated by a porous polycarbonate membrane and connected to the chip via a $1-\mathrm{mL}$ syringe. The syringe separates the cell culture medium in the chip from the electrolyte in the pump and allows the flow to be viewed and tracked during this characterization, but could be eliminated or redesigned to reduce the dead volume even further. To test the function of the pump, we used it with two differently sized microfluidic devices to control the motion of both micro- and macroscale particles, as well as for stimulating endothelial cells exerting them to shear stress of about $\pm 5 \mathrm{dyn} / \mathrm{cm}^{2}$ at $0.1 \mathrm{~Hz}$. 


\section{Experimental}

\subsection{Electroosmotic pump}

The design of the pump and the microfluidic setup is shown together in Fig. 1. The pump consisted of a hydrophilic polycarbonate membrane (IpPore ${ }^{\mathrm{TM}}$, pore diameter $0.2 \mu \mathrm{m}$, diameter $25 \mathrm{~mm}, 5 \times 10^{8}$ pores $/ \mathrm{cm}^{2}$ ) placed between two poly(3,4-ethylenedioxythiophene) electrodes, each mechanically supported by a loosely woven nylon textile. This stack was placed in a $25-\mathrm{mm}$ membrane syringe filter holder (Sartorius). To allow electrical connection, a 5-mm-wide strip of each electrode exited the filter holder where the threads had been removed to prevent tearing of the electrode during assembly. To protect the electrode strip that passes through the threads of the filter holder and minimize the fluid that "leaks" through the material, this strip was coated with a conducting carbon paste (Leit C Conducting Carbon Cement, Neubauer Chemikalien), followed by melted paraffin wax and a layer of vacuum grease (High vacuum grease, Dow Corning ${ }^{\circledR}$ ).

The electrodes were prepared by applying $0.1-0.2 \mathrm{~g} /$ $\mathrm{cm}^{2}$ (wet) PEDOT:PSS on the nylon textile. These were then baked at $50{ }^{\circ} \mathrm{C}$ for $2 \mathrm{~h}$, followed by a temperature ramp of $3.6{ }^{\circ} \mathrm{C} \mathrm{h}^{-1}$ to $90{ }^{\circ} \mathrm{C}$, finishing with $90{ }^{\circ} \mathrm{C}$ for $5 \mathrm{~h}$. After cooling to room temperature, the electrodes were rinsed in $0.1 \mathrm{M} \mathrm{NaCl}$ for $16 \mathrm{~h}$ and neutralized (to $\mathrm{pH} \sim 7$ ) using $0.1 \mathrm{M} \mathrm{NaOH}$ before assembly with the membrane in the syringe filter holder.

\subsection{Cell culture}

Human umbilical vein endothelial cells (HUVECs, ThermoFisher) were used at passage 3 or 4 and cultured in Medium 200 (ThermoFisher) supplemented with low serum growth supplement (LSGS, ThermoFisher). For flow experiments, the cells were trypsinized, centrifuged and resuspended in cell culture medium at a concentration of $15 \times 10^{6}$ cells $/ \mathrm{mL}$. To minimize the risk of air bubble formation in the channels, the microfluidic slides and cell culture medium were both incubated at $37{ }^{\circ} \mathrm{C}$ overnight. The cells were seeded in pre-coated microfluidic channels $(\mu$-slide $\mathrm{VI}^{0.1}$, IbiTreat, Ibidi) using a 1-mL syringe and were allowed to attach for at least $2 \mathrm{~h}$ before new cell culture medium was added to the reservoirs of the slide. If the slides were not used for flow experiments the same day, they were placed on a rocking platform to stir the culture medium. Live/Dead assays were performed using calcein and ethidium homodimer-1 (both from LifeTechnologies) and Hoechst 33,342 (ThermoFisher) to stain the nuclei. The cells were visualized in a confocal microscope (Zeiss Axio Observer.Z1, LSM700). Images were processed using ImageJ software (NIH).

\subsection{Flow experiments}

One-microliter syringes were attached to microfluidic channels with height of $100 \mu \mathrm{m}$ (cross-sectional area $0.1 \mathrm{~mm}^{2}$, $\mu$-Slide $\mathrm{VI}^{0.1}$ ) and seeded with HUVECs or microparticles (20 $\mu \mathrm{m}$, microparticles GMBH), or a height of $400 \mu \mathrm{m}$ (cross-sectional area $1.52 \mathrm{~mm}^{2}, \mu$-Slide $\mathrm{VI}^{0.4}$, untreated, Ibidi) and filled with microparticles $(20 \mu \mathrm{m}$, microparticles
Fig. 1 Pump and cell culture chip assembly. a Photograph of the electroosmotic pump incorporated into a modified syringe filter holder and connected onto a microfluidic device filled with blue dye. The syringe barrel on the left side of the channel was used to balance the hydrostatic pressure. b Exploded schematic of the pump in a modified syringe filter holder. The electroosmotic pump consisted of a track-etched polycarbonate membrane sandwiched by two PEDOT:PSS electrodes (color figure online)

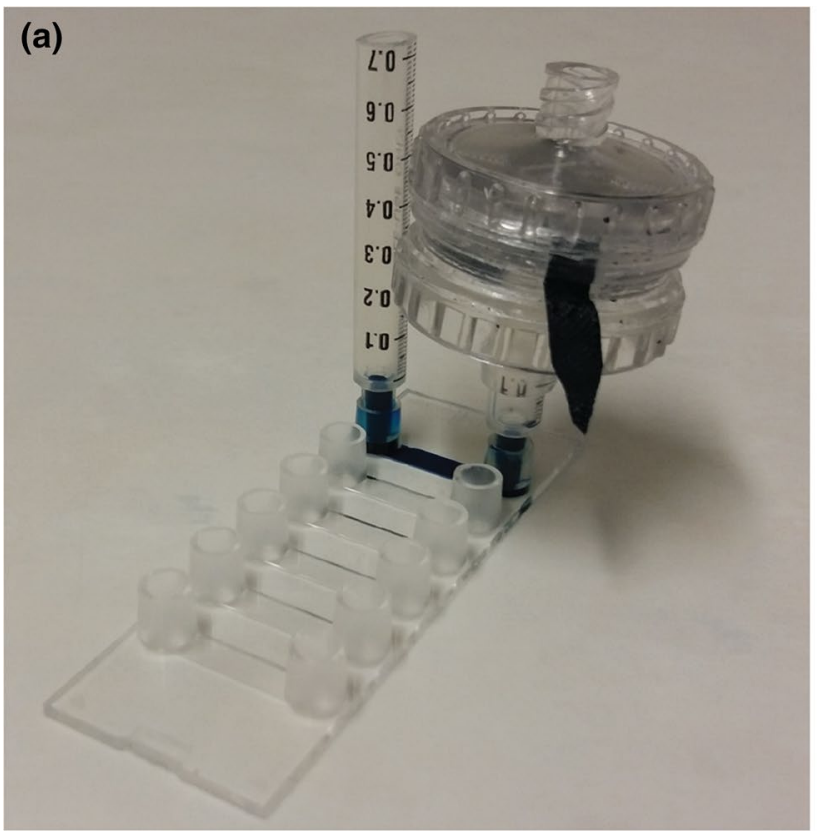


GMBH), or macroparticles (100 $\mu \mathrm{m}$, CultiSpher ${ }^{\mathrm{TM}}$, Percell Biolytica). All equipment was either acquired sterile or rinsed in ethanol prior to use. The pump was connected to a shortened syringe holding a volume of about $200 \mu \mathrm{L}$ and contained a bubble of approximately $100 \mu \mathrm{L}$ to separate the buffer in the pump ( $1 \mathrm{mM}$ TrisHCl, Trizma ${ }^{\circledR}$ base, Sigma, $\mathrm{pH}$ 7) from the cell culture medium in the chip and allow the displacement of fluid to be easily monitored. Note that this, relatively large, additional piece is only necessary when calibrating the pump. Normally the pump can be placed directly on the chip, and the bubble separating the fluids can reside in the Luer connector. The assembly was placed on a microscope heating insert $\left(37^{\circ} \mathrm{C}\right)$ on top of a microscope (SVM340, Labsmith). Before starting the pump, the levels in the two syringe reservoirs were adjusted until there was no visible pressure-driven flow through the fluidic channel. The motion of the bubble in the syringe connected to the pump was tracked using a camera (DinoLite Pro), allowing the flow rate to be estimated during the experiment and carefully analyzed afterwards. The videos recorded were used to determine the vertical position of the center and edge of the top meniscus, using MATLAB, with an estimated accuracy of about $0.1 \mathrm{~mm}(2 \mu \mathrm{L})$. These data were used to calculate the volumetric flow rate and pressure drop over the meniscus interface.

\subsection{Image analysis and statistics}

To better visualize the cell morphology in the Live/Dead assay, the green channel (showing cell cytosol) was convoluted with a $5 \times 5$ high-pass filter. The mean and SD of the area and shape index of 150 cell nuclei, and the cell surface coverage at three locations, were measured using ImageJ. The shape index indicates the circularity of the nucleus, where the maximum 1 represents a perfect circle. Differences in the populations were analyzed by the nonparametric Mann-Whitney test for area and Student's $t$ test for shape index and the surface coverage, and considered significant for $p<0.01$.

\section{Results and discussion}

\subsection{Design and performance of the electroosmotic pump}

The pump was designed to easily connect to commercial microfluidic devices and operate at high flow rates. Furthermore, it was designed to overcome previously reported limitations of EOPs: electrolysis of water at high voltages, risk of electrical damage to cells, fouling of the membrane by impurities from the pump fluid or cell culture medium, and poor performance with the salt concentration of cell culture medium (Byun et al. 2014).

These criteria resulted in a design for an EOP integrated onto the Luer connector of a commercially available microfluidic channel (Fig. 1). A porous polycarbonate membrane was sandwiched between two pieces of PEDOT:PSS-coated nylon fabric. Each pore in the membrane functions as an EOP, i.e., the volumetric flow rate is proportional to the pore density. The flexibility of the polycarbonate membrane, the nylon fabric and the polymer used in the electrodes allowed the incorporation of the pump into a syringe filter holder with access to one electrode on each side. To separate the cell culture medium from the pump solution, approximately $100 \mu \mathrm{L}$ of air was drawn into the syringe that connected the pump to the Luer coupling on the chip. On the other side of the channel, medium is placed in a second syringe to balance gravity-induced pressure. The flow generated by the pump is quantified in Fig. 2. A maximum flow rate of $\sim 400 \mu \mathrm{L} / \mathrm{min}$ at $\pm 5 \mathrm{~mA}$ was achieved when the resistance to flow was minimized, i.e., the pump was connected to the $\mu$-Slide $\mathrm{VI}^{0.4}$, compared to a maximum flow rate of $\sim 90 \mu \mathrm{L} /$ min at $\pm 5 \mathrm{~mA}$ when connected to the $\mu$-Slide $\mathrm{VI}^{0.1}$. When operated at $\pm 5 \mathrm{~mA}$, the applied potential reached a maximum of about $2.5 \mathrm{~V}$, making the peak power consumption about $13 \mathrm{~mW}$. The electroosmotic mobility $\mu_{\mathrm{eo}}$ was estimated by linear regression of flow velocity versus the mean applied potential, resulting in $\mu_{\mathrm{eo}}=(3.86 \pm 0.22) \times 10^{-10}$ $\mathrm{m}^{2} / \mathrm{V} \mathrm{s}$, similar to what has been measured during previous characterization of the membrane-based pumping setup (Bengtsson and Robinson 2017). This value corresponds to

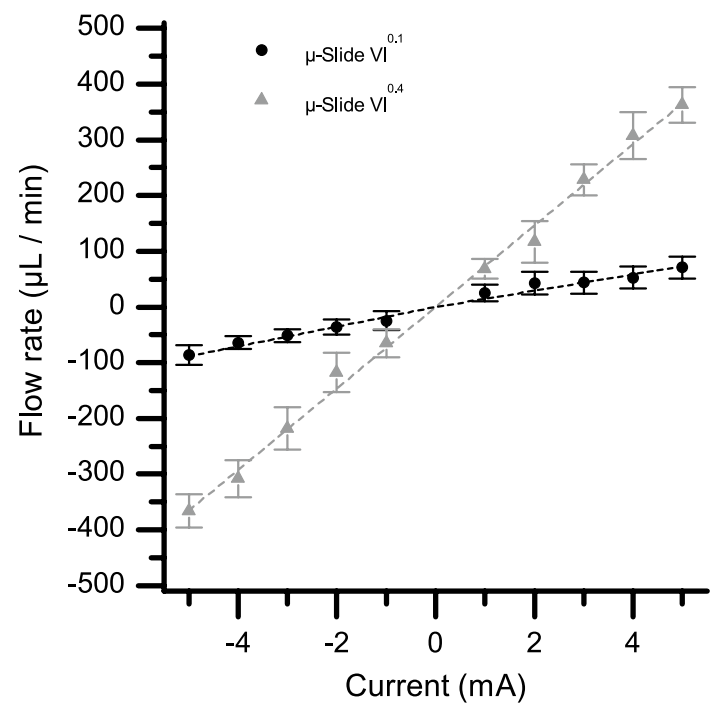

Fig. 2 Average volumetric flow rate $(N=3)$ versus current for two different configurations: connected to a $\mu$-Slide $\mathrm{VI}^{0.4}$ (gray triangles) and connected to a $\mu$-Slide $\mathrm{VI}^{0.1}$ (black circles), pumping $1 \mathrm{mM}$ TrisHCl, $(\mathrm{pH} 7.1 \pm 0.1)$ in each case. Dashed lines represent linear fits (through the origin) of each data set. Error bars indicate $\pm 1 \mathrm{SD}$ 
a $\zeta$ potential of $-0.55 \pm 0.03 \mathrm{mV}$, calculated according to $\zeta=-u_{\mathrm{eo}} \eta /\left(\varepsilon_{r} \varepsilon_{0}\right)$ where the solution viscosity $\eta=1.01 \mathrm{cP}$ (Haynes et al. 2015) and the relative dielectric constant $\varepsilon_{r}=80$ (Kirby 2010; Nörtemann et al. 1997). We estimate (but did not measure) a maximum hydrostatic pressure (at zero flow) to be approximately $100 \mathrm{~mm} \mathrm{H}_{2} \mathrm{O}$ per $\mathrm{V}$ of applied potential based on our previous pump characterization (Bengtsson and Robinson 2017) with a similar pump membrane that had double the pore diameter and a maximum pressure of $25 \mathrm{mmH}_{2} \mathrm{O} / \mathrm{V}$. (Halving the diameter theoretically increases the maximum pressure $4 \times$.) The pressure drop across the top meniscus of the bubble in the syringe was estimated from the meniscus curvature and surface tension of the air-water interface to be at most $70 \mathrm{~Pa}$.

The oscillatory flow of the pump was also verified using micro- and macroparticles (20 and $100 \mu \mathrm{m}$ in diameter, respectively) under oscillation between 0.1 and $0.25 \mathrm{~Hz}$, see Supplementary information videos 1 and 2 . The maximum microparticle velocity corresponded to a volumetric flow rate of $100 \mu \mathrm{L} / \mathrm{min}$ at $\pm 5 \mathrm{~mA}$ in the $\mu$-Slide $\mathrm{VI}^{0.1}$.

The pump initially generated a flow rate of $90 \mu \mathrm{L} / \mathrm{min}$, but stabilized at $60 \mu \mathrm{L} / \mathrm{min}$ within $16 \mathrm{~h}$ with consistent flow rates over the next $48 \mathrm{~h}$ at $\pm 5 \mathrm{~mA}$. The decreasing flow rate was probably caused by decreasing $\mathrm{pH}$ in the pump electrolyte. The electrolyte in the pump started with a $\mathrm{pH}$ of 7 , and for the instances when the flow rate decreased, the $\mathrm{pH}$ was found to be between 4.8 and 5.8 after the experiment. The $\mathrm{pH}$ changes may have been caused by water electrolysis or leeching of $\mathrm{H}^{+}$from the PEDOT:PSS electrodes. The generation of $\mathrm{pH}$ changes by water electrolysis in the pump electrolyte can be reduced by increasing the mass (thickness), and concomitantly the columbic capacity, of the polymer used in the electrodes. The leeching of protons from the PSS in the electrodes can be minimized via electrochemical ion exchange before assembly, or through continued operation in the pump (as long as the pump electrolyte is replaced). The impact of either mechanism can likely be reduced by decreasing the initial $\mathrm{pH}$ of the pump electrolyte and/or adding $\mathrm{pH}$ buffer to the electrolyte. Replacing the electrolyte in the pump restored the pump's performance, increasing the flow rate to the starting value. This implies that the flow rate could be further increased by increasing the $\mathrm{pH}$ of the electrolyte in the pump and shows the importance of minimizing electrolysis in the pump. No decrease in flow rate was observed during the calibration measurements taken to collect the data in Fig. 2, which only took about an hour. Modifying or replacing the porous polycarbonate membrane in this pump could increase the volumetric flow rate, e.g., through increasing the porosity of the membrane or increasing the surface charge density.

By separating the pump electrolyte from the cell media in the chip, we eliminated the risk of any electrolytic byproducts or residue from the PEDOT:PSS electrodes contacting the cells. The separate electrolyte also allowed us to use a low (nonphysiological) concentration of salt in the pump, increasing the pump's performance and reducing the risk of clogging of the membrane with cell proteins and debris.

\subsection{Inducing shear stress on endothelial cells with the pump}

To investigate the performance and compatibility of the EOP with cultured cells, human endothelial cells (HUVECs) were exposed to oscillating flow generated by the pump. As described previously, these cells were expected to respond to shear stress. We hypothesized that the EOP would produce a sufficient flow to induce a physiological change in the cells. Based on previously reported shear stress studies on in vivo veins, and reports of shear stress used to induce morphological changes in endothelial cells, we aimed to achieve a shear stress of at least $\pm 5 \mathrm{dyn} / \mathrm{cm}^{2}$ (Malek et al. 1999; Schimek et al. 2013). The HUVECs were seeded in microfluidic channels and exposed to an alternating shear stress of at least $\pm 5 \mathrm{dyn} / \mathrm{cm}^{2}$ (high shear, $\sim 60 \mu \mathrm{L} / \mathrm{min}$ ) or $\pm 2.2 \mathrm{dyn} /$ $\mathrm{cm}^{2}$ (low shear, $\sim 25 \mu \mathrm{L} / \mathrm{min}$ ) by driving currents at \pm 5 or $\pm 2 \mathrm{~mA}$, respectively, for $5 \mathrm{~s}$ in each direction $(0.1 \mathrm{~Hz})$. As previously explained, the flow rate generated by driving the pump at $\pm 5 \mathrm{~mA}$ started at $\sim 90 \mu \mathrm{L} / \mathrm{min}$ or $\pm 7 \mathrm{dyn} /$ $\mathrm{cm}^{2}$, but decreased over time before stabilizing at $60 \mu \mathrm{L} / \mathrm{min}$ within $16 \mathrm{~h}$. No decrease in flow rate over time was observed when driving the flow at $\pm 2 \mathrm{~mA}$. The viability of the cells after $48 \mathrm{~h}$ of pumping was confirmed with a Live/Dead assay (Fig. 3). As expected, the endothelial cells did not align in the direction of the oscillatory flow (see Fig. 3 and supplementary video 3 ). However, the mean area and shape index of the cell nuclei and the total cell coverage were all statistically different between cells exposed to high $\left(5 \mathrm{dyn} / \mathrm{cm}^{2}\right)$ and low (2.2 dyn $/ \mathrm{cm}^{2}$ ) oscillating shear (see Fig. 4). Morphological changes in the cell nucleus area and decreased permeability due to an increased membrane integrity have previously been attributed to shear stress from laminar flow on endothelial cells (Booth and Kim 2012; Deguchi et al. 2005). Furthermore, the high level of oscillatory shear appears to induce enlargement and stretching of the cells, as well as a decrease in the number of nuclei, as shown in Fig. 3. This has previously been explained by a decrease in the growth rate of endothelial cells due to high shear stress (Li et al. 2005; Malek et al. 1999). Consequently, fewer cells occupy the same area and can therefore become larger and potentially also elongated. 
High shear stress

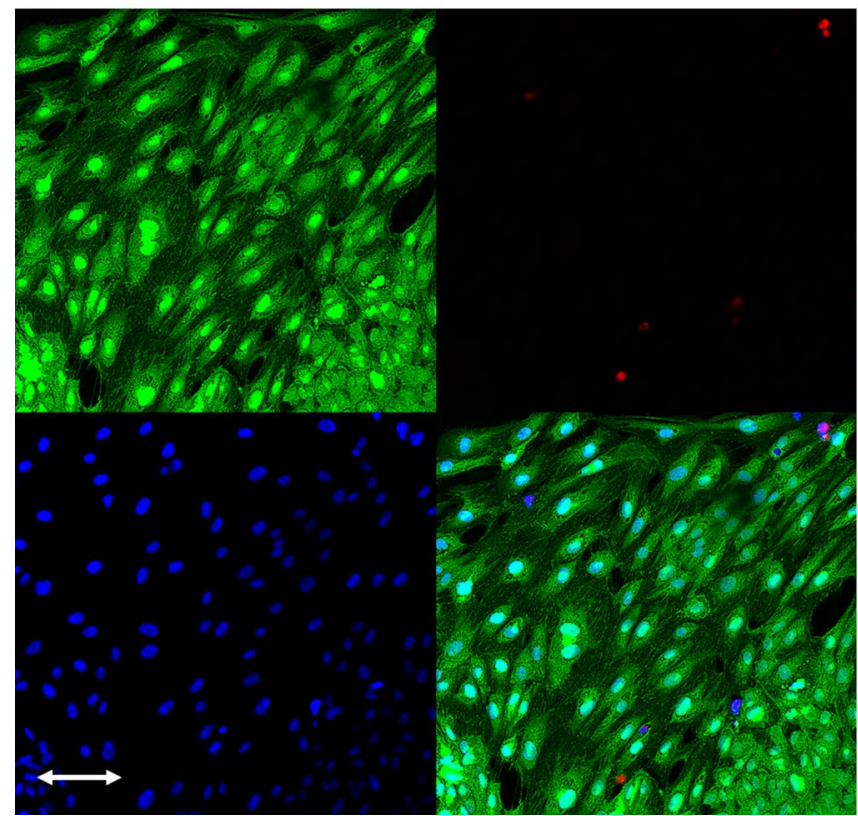

Fig. 3 Live/Dead assay after $48 \mathrm{~h}$ of alternating flow at $\pm 5 \mathrm{dyn} / \mathrm{cm}^{2}$ (high shear, left) and at $\pm 2.2 \mathrm{dyn} / \mathrm{cm}^{2}$ (low shear, right) showing living cells in green, dead cells in red, and cell nuclei in blue, each
Low shear stress

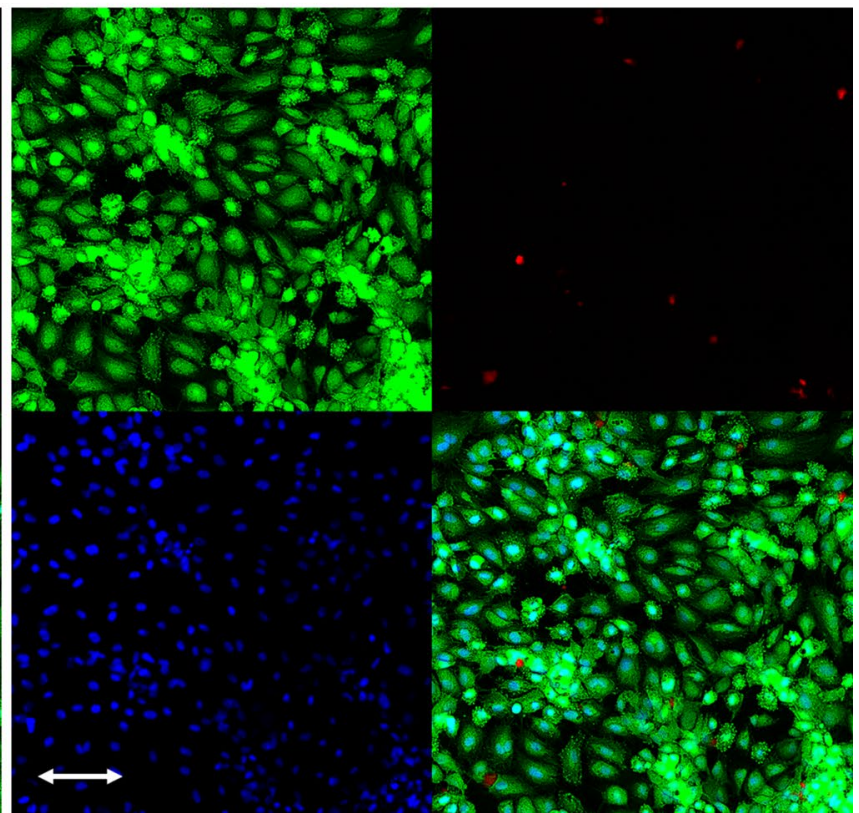

through a $10 \times$ objective. Each color channel is shown separately, and then as a composite (bottom right). The arrow indicates the direction of the oscillating flow and a length of $100 \mu \mathrm{m}$ (color figure online)
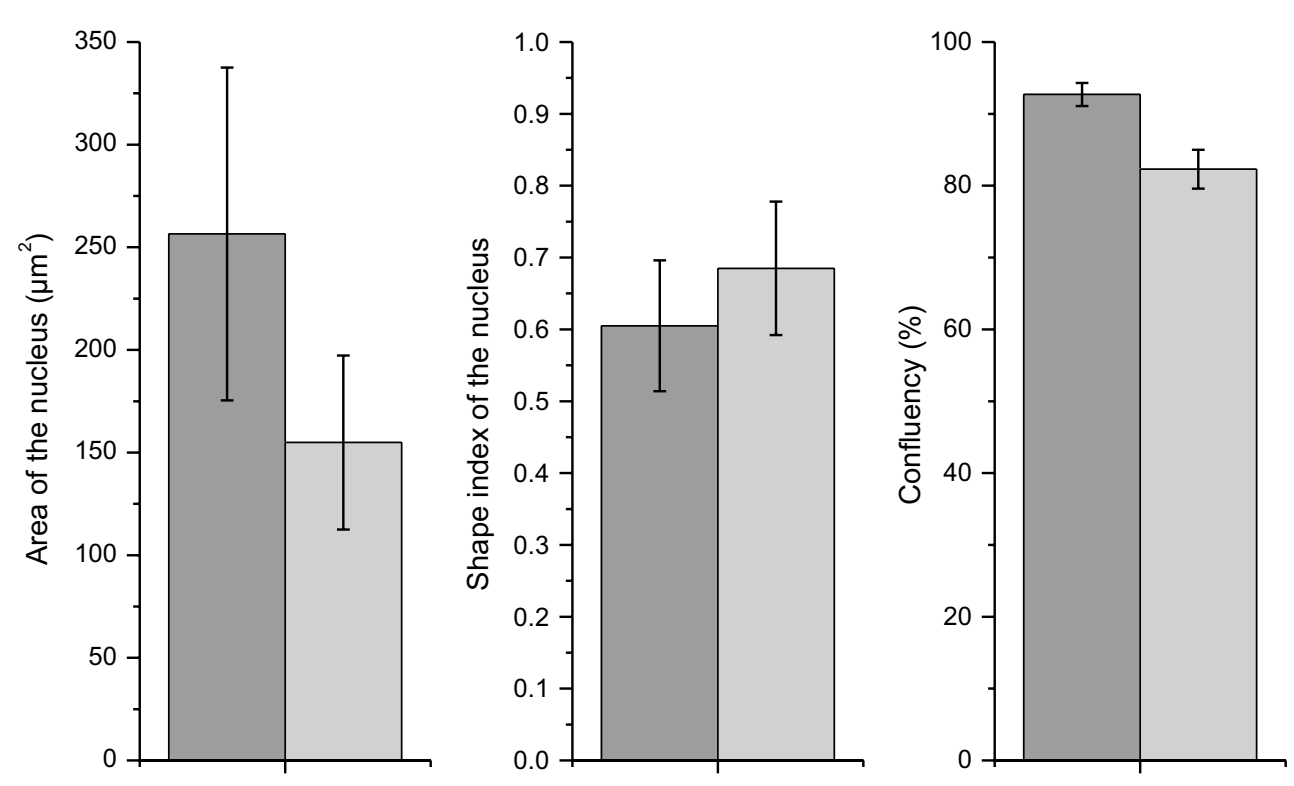

Fig. 4 Mean and SD cell nucleus area, shape index, and cell surface coverage (confluency) for cells exposed to low $\left( \pm 2.2 \mathrm{dyn} / \mathrm{cm}^{2}\right)$ and high $\left( \pm 5 \mathrm{dyn} / \mathrm{cm}^{2}\right)$ alternating shear. The high shear stress signifi- cantly affected the cell nucleus morphology (area and shape of the nucleus) and the confluency 


\section{Conclusion}

The broad adoption of highly parallelized chemical and biological flow experiments for applications such as pharmaceutical testing has, in part, been limited by the need for external appliances such as pumps. When designing such a system, one must typically choose between on-chip pumps, which require the fabrication of relatively expensive, highly specialized chips, and remote pumps that must be connected via tubing and dramatically increase the volume of each flow circuit. For practical and commercial reasons, the entire fluidic setup surrounding microfluidic devices should be well integrated into the device and the various operative components such as pumps and detectors should be approximately the same size as the chip itself. Ideally, the fluidic setup should be able to provide a wide range of flow rates while minimizing the volume of liquid, and the quantity of costly pharmaceuticals, required.

In this paper, we have presented an oscillating electroosmotic pump that fits onto connectors typical of commercially available microfluidic chips. The pump, which is less than half the size of the chip used in this study, was able to drive cell medium at flow rates up to $400 \mu \mathrm{L} / \mathrm{min}$ through a microfluidic channel with a cross-sectional area of $1.52 \mathrm{~mm}^{2}$, and up to $90 \mu \mathrm{L} / \mathrm{min}$ through an area of $0.1 \mathrm{~mm}^{2}$. These volumetric flow rates were sufficient to induce an apparent morphological response of endothelial cells by exposing them to an alternating shear stress of $\pm 5 \mathrm{dyn} / \mathrm{cm}^{2}$ for $48 \mathrm{~h}$. The pump delivered reproducible flow rates and maintained the cells for over $96 \mathrm{~h}$. These performance properties make the EOP a viable alternative for a variety of microfluidic configurations.

Acknowledgements This work was funded by the Swedish Research Council (Vetenskapsrådet) Grant 2015-03298. We thank Kjersti Claesson and Maria Wahlstedt for lending us the heater used on the microscope.

\section{Compliance with ethical standards}

Conflict of interest NDR and KB have a stake in LunaMicro $A B$, which owns a patent protecting the use of electrochemically active electrodes in electrokinetic devices.

Open Access This article is distributed under the terms of the Creative Commons Attribution 4.0 International License (http://creativeco mmons.org/licenses/by/4.0/), which permits unrestricted use, distribution, and reproduction in any medium, provided you give appropriate credit to the original author(s) and the source, provide a link to the Creative Commons license, and indicate if changes were made.

\section{References}

Bengtsson K, Robinson ND (2017) A large-area, all-plastic, flexible electroosmotic pump. Microfluid Nanofluid 21:178. https://doi. org/10.1007/s10404-017-2017-1

Bengtsson K, Nilsson S, Robinson ND (2014) Conducting polymer electrodes for gel electrophoresis. PloS one 9:e89416. https://doi. org/10.1371/journal.pone.0089416

Booth R, Kim H (2012) Characterization of a microfluidic in vitro model of the blood-brain barrier ([small mu]BBB). Lab Chip 12:1784-1792. https://doi.org/10.1039/C2LC40094D

Brask A, Kutter JP, Bruus H (2005) Long-term stable electroosmotic pump with ion exchange membranes. Lab Chip 5:730. https://doi. org/10.1039/b503626g

Byun CK, Abi-Samra K, Cho Y-K, Takayama S (2014) Pumps for microfluidic cell culture. Electrophoresis 35:245-257. https://doi. org/10.1002/elps.201300205

Chang JY et al (2014) A novel miniature dynamic microfluidic cell culture platform using electro-osmosis diode pumping. Biomicrofluidics 8:044116. https://doi.org/10.1063/1.4892894

Davies PF, Civelek M, Fang Y, Fleming I (2013) The atherosusceptible endothelium: endothelial phenotypes in complex haemodynamic shear stress regions in vivo. Cardiovasc Res 99:315-327. https:// doi.org/10.1093/cvr/cvt101

Deguchi S, Maeda K, Ohashi T, Sato M (2005) Flow-induced hardening of endothelial nucleus as an intracellular stress-bearing organelle. J Biomech 38:1751-1759. https://doi.org/10.1016/j.jbiom ech.2005.06.003

Emmelkamp J, Wolbers F, Andersson H, DaCosta RS, Wilson BC, Vermes I, van den Berg A (2004) The potential of autofluorescence for the detection of single living cells for label-free cell sorting in microfluidic systems. Electrophoresis 25:3740-3745. https://doi.org/10.1002/elps.200406070

Erlandsson PG, Robinson ND (2011) Electrolysis-reducing electrodes for electrokinetic devices. Electrophoresis 32:784-790

Esch MB et al (2015) Multi-cellular 3D human primary liver cell culture elevates metabolic activity under fluidic flow. Lab Chip 15:2269-2277. https://doi.org/10.1039/c5lc00237k

Franzoni M, Cattaneo I, Longaretti L, Figliuzzi M, Ene-Iordache B, Remuzzi A (2016) Endothelial cell activation by hemodynamic shear stress derived from arteriovenous fistula for hemodialysis access. Am J Physiol Heart Circ Physiol 310:H49

Glawdel T, Elbuken C, Lee LEJ, Ren CL (2009) Microfluidic system with integrated electroosmotic pumps, concentration gradient generator and fish cell line (RTgill-W1)-towards water toxicity testing. Lab Chip 9:3243-3250. https://doi.org/10.1039/B911412M

Haynes WMB, Tomas J, Lide DR (2015) CRC handbook of chemistry and physics, 96th edn. CRC Press, Boca Raton

Huang P-H et al (2014) A reliable and programmable acoustofluidic pump powered by oscillating sharp-edge structures. Lab Chip 14:4319-4323. https://doi.org/10.1039/C4LC00806E

Jackman CP, Carlson AL, Bursac N (2016) Dynamic culture yields engineered myocardium with near-adult functional output. Biomaterials 111:66-79. https://doi.org/10.1016/j.biomateria 1s.2016.09.024

Jang K-J, Mehr AP, Hamilton GA, McPartlin LA, Chung S, Suh K-Y, Ingber DE (2013) Human kidney proximal tubule-on-a-chip for drug transport and nephrotoxicity assessment. Integr Biol 5:11191129. https://doi.org/10.1039/C3IB40049B

Kirby BJ (2010) Micro- and nanoscale fluid dynamics, 1st edn. Cambridge University Press, New York

Kwon K, Park C-W, Kim D (2012) High-flowrate, compact electroosmotic pumps with porous polymer track-etch membranes. Sens Actuat A Phys 175:108-115. https://doi.org/10.1016/j. sna.2011.12.050 
Li PCH, Harrison DJ (1997) Transport, manipulation, and reaction of biological cells on-chip using electrokinetic effects. Anal Chem 69:1564-1568. https://doi.org/10.1021/ac9606564

Li Y-SJ, Haga JH, Chien S (2005) Molecular basis of the effects of shear stress on vascular endothelial cells. J Biomech 38:19491971. https://doi.org/10.1016/j.jbiomech.2004.09.030

Malek AM, Alper SL, Izumo S (1999) Hemodynamic shear stress and its role in atherosclerosis. JAMA 282:2035-2042. https://doi. org/10.1001/jama.282.21.2035

Nilsson S, Erlandsson PG, Robinson ND (2015) electroosmotic pumps with frits synthesized from potassium silicate. PloS one 10:e144065. https://doi.org/10.1371/journal.pone.0144065

Nörtemann K, Hilland J, Kaatze U (1997) Dielectric properties of aqueous $\mathrm{NaCl}$ solutions at microwave frequencies. J Phys Chem A 101:6864-6869

Sachan VK, Singh AK, Jahan K, Kumbar SG, Nagarale RK, Bhattacharya PK (2014) Development of redox-conducting polymer electrodes for non-gassing electro-osmotic pumps: a novel approach. J Electrochem Soc 161:H3029-H3034. https://doi. org/10.1149/2.0071413jes
Schimek K et al (2013) Integrating biological vasculature into a multiorgan-chip microsystem. Lab Chip 13:3588-3598. https://doi. org/10.1039/C3LC50217A

Snyder JL et al (2013) High-performance, low-voltage electroosmotic pumps with molecularly thin silicon nanomembranes. Proc Natl Acad Sci 110:18425-18430. https://doi.org/10.1073/pnas.13081 09110

Suzuki H, Yoneyama R (2003) Integrated microfluidic system with electrochemically actuated on-chip pumps and valves. Sens Actuators B Chem 96:38-45. https://doi.org/10.1016/S0925 $-4005(03) 00482-9$

Unger MA, Chou H-P, Thorsen T, Scherer A, Quake SR (2000) Monolithic microfabricated valves and pumps by multilayer soft lithography. Science 288:113-116. https://doi.org/10.1126/scien ce.288.5463.113

Xuan X, Li D (2005) Focused electrophoretic motion and selected electrokinetic dispensing of particles and cells in cross-microchannels. Electrophoresis 26:3552-3560. https://doi.org/10.1002/ elps. 200500298 